\title{
Non invasive quantification of coronary endothelial function using 3
}

T MRI

\author{
Pierre-Julien Moro*1, Alexis Jacquier ${ }^{1}$, Frank Kober ${ }^{1}$, Jean-Louis Bonnet ${ }^{2}$, \\ Patrick J Cozzone ${ }^{1}$ and Monique Bernard ${ }^{1}$
}

\author{
Address: ${ }^{1}$ Centre de Résonance Magnétique Biologique et Médicale, CNRS UMR 6612, Université de la Méditerranée, Marseille, France and \\ ${ }^{2}$ Département de Cardiologie adulte, CHU Timone, Marseille, France \\ * Corresponding author
}

from 13th Annual SCMR Scientific Sessions

Phoenix, AZ, USA. 21-24 January 2010

Published: 21 January 2010

Journal of Cardiovascular Magnetic Resonance 2010, I2(Suppl I):O75 doi:I0.I I86/1532-429X-12-SI-O75

This abstract is available from: http://jcmr-online.com/content/I2/SI/O75

(c) 2010 Moro et al; licensee BioMed Central Ltd.

\section{Introduction}

Endothelial dysfunction (ED) plays a key role in the development of cardiovascular disease; a non invasive MRI method of quantification of coronary ED would be relevant for risk stratification, treatment, monitoring and prognosis evaluation in several diseases involving ED.

\section{Purpose}

To evaluate the feasibility of assessing coronary endothelial function by myocardial blood flow (MBF) measurement using coronary sinus flow quantification $[1,2]$ at rest and during cold pressor test (CPT), which is used in nuclear medicine to assess endothelium-dependent coronary vasomotor function.

\section{Materials and methods}

Thirteen healthy volunteers (ten men, three women) without any coronary risk factors underwent magnetic resonance imaging in a $3 \mathrm{~T}$ scanner (Verio, Siemens, Erlangen, Germany). СРT was performed by immersing the right ankle in ice-water during four minutes. Heart rate and blood pressure were monitored throughout the protocol using a Maglife system (Schiller). Coronary sinus flow was measured at rest and during CPT using non breath-hold velocity encoded phase contrast cine MRI (repetition time/echo time: $45 \mathrm{~ms} / 2 \mathrm{~ms}$, slice thickness: $5.5 \mathrm{~mm}$, field of view: $250 \times 250 \mathrm{~mm}^{2}$, averages: 11 , matrix: $256 \times 256$, flow encoding: $70 \mathrm{~cm} / \mathrm{sec}$, flip angle: $25^{\circ}$, acquisition time: 4 minutes, GRAPPA k-space reduc- tion factor: 4). Myocardial function and morphology were evaluated using SSFP sequence. MBF was calculated combining coronary sinus flow quantification and morphologic data using Argus software (flow and 2D). Coronary endothelial function was assessed by comparing MBF at rest and during CPT. Coronary vascular resistance (CVR) and endothelium-dependent vasodilation index (EDVI) were calculated.

\section{Results}

Each volunteer tolerated CPT. CPT significantly increased heart rate by $32 \%(\mathrm{p}<0.0001)$, systolic blood pressure by $20 \%(\mathrm{p}<0.0001)$ and significantly decreased CVR by $18 \%(\mathrm{p}=0.021)$. At baseline, coronary blood flow per gram of myocardial mass was $0.61 \pm 0.18 \mathrm{ml} / \mathrm{min} / \mathrm{g}$ $($ mean $\pm \mathrm{SD})$. After CPT, coronary blood flow was $1.01 \pm$ $0.41 \mathrm{ml} / \mathrm{min} / \mathrm{g}$. MBF significantly increased by $65 \pm 43 \%$ during CPT compared to the rest examination $(p<$ 0.0011). EDVI was 1.65. Figure 1.

\section{Conclusion}

MRI coronary sinus flow quantification as a measure of the myocardial blood flow without contrast agent allows to detect significant changes in response to CPT in healthy volunteers. This non invasive measure may help to detect changes in endothelial function which occur early in a variety of cardiovascular diseases. 


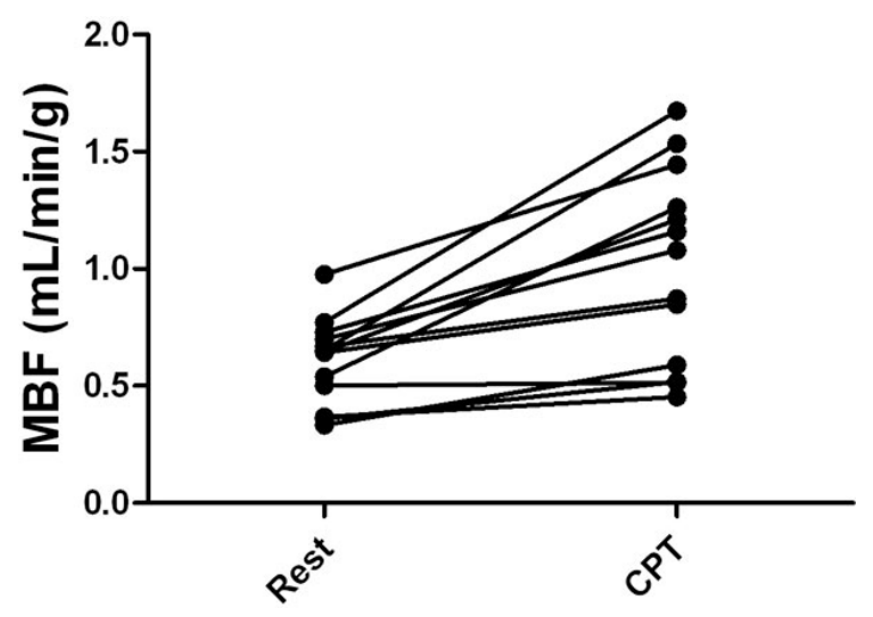

Figure I

MBF values at rest and after CPT in each healthy volunteer.

\section{References}

I. van Rossum, et al.: Radiology 1992, 182:685-69|.

2. Lund GK, et al.: Radiology 2003, 227:209-215.

Publish with Bio Med Central and every scientist can read your work free of charge

"BioMed Central will be the most significant development for disseminating the results of biomedical research in our lifetime."

Sir Paul Nurse, Cancer Research UK

Your research papers will be:

- available free of charge to the entire biomedical community

- peer reviewed and published immediately upon acceptance

- cited in PubMed and archived on PubMed Central

- yours - you keep the copyright 